\title{
Método para avaliação e pesquisa da atividade antimicrobiana de produtos de origem natural
}

\author{
Janaina F. Packer ${ }^{1, *}$, Marisa M.S. da Luz ${ }^{2}$ \\ ${ }^{1}$ Pós-Graduação em Microbiologia, Pontifícia Universidade Católica do Paraná, Rua Imaculado \\ Conceição, 1155, Prado Velho, 80215-901, Curitiba, PR, Brasil, \\ ${ }^{2}$ Laboratório de Controle de Qualidade e Pesquisa Ltda, Rua Comendador Roseira, 342, Prado Velho, \\ 80215-210, Curitiba, PR, Brasil
}

\begin{abstract}
RESUMO: As exigências do mercado consumidor induzem a indústria cosmética a formular produtos seguros cada vez menos agressivos e naturais. Durante a formulação para tais apelos a dificuldade maior encontra-se em conservar o produto final. Com este objetivo avaliamos os óleos: de copaíba, alecrim, melaleuca, alho, andiroba; própolis, e dois ingredientes de origem natural: um ingrediente multifuncional extraído de folhas de oliva e o farnesol que estão disponíveis e são fornecidos à indústria cosmética, com a finalidade de comprovar a ação dos mesmos. O método de escolha foi o de ágar em placa com orifício modificado. As cepas selecionadas foram Staphylococcus aureus (ATCC 6538), Escherichia coli (ATCC 8739), Pseudomonas aeruginosa (ATCC 9027) e Candida albicans (ATCC 10231). Dentre as amostras analisadas os melhores resultados foram obtidos com os óleos de melaleuca e alecrim que apresentaram atividade bacteriostática e fungistática para as quatro cepas em questão.
\end{abstract}

Unitermos: Própolis, óleo de melaleuca, óleo de alecrim; óleo de copaíba, óleo de alho, óleo de andiroba.

\begin{abstract}
Evaluation and research method for natural products inhibitory activity". The consumer market requirement induces the cosmetic industry to generate safer and less aggressive products including the natural products. Within the natural products formulation process, the most demanding challenge is the final product conservation. In order to cope with the conservation factor, some natural oils (copaiba, rosemary, melaleuca, garlic, andiroba), propolis and two natural ingredients (one multifunctional ingredient extracted from olive leaves and farnesol) which are available and usually supplied to the cosmetic industry, were considered in this analysis. The chosen method was the agar in plaque with modificed hole. The chosen microorganisms were: Staphylococcus aureus (ATCC 6538), Escherichia coli (ATCC 8739), Pseudomonas aeruginosa (ATCC 9027) and Candida albicans (ATCC 10231). The best results were achieved by melaleuca and rosemary oils, which showed bacteriostatic and fungistatic activity against the four microorganisms.
\end{abstract}

Keywords: Propolis, melaleuca oil, rosemary oil, copaiba oil, garlic oil, andiroba oil.

\section{INTRODUÇÃO}

$\mathrm{O}$ consumidor tem se tornado cada vez mais exigente e mais criterioso com a qualidade do produto que consome. É crescente a sua preocupação em fazer uso de produtos menos agressivos de origem natural ou o mais próximo possível desta origem. Esta é a realidade à qual está submetida, também, a indústria cosmética; formulação de produtos naturais, portanto a não inclusão de matérias primas sintéticas para, por exemplo, conservação do produto final. Neste quesito são poucas as formulações que resistem à primeira inoculação quando do Teste de Desafio do Conservante. Por tal motivo remetese à pesquisa de produtos extraídos de fitoterápicos e produtos naturais com valor conhecido, comprovado ou não, que são ofertados à indústria cosmética.
Um dos melhores exemplos são produtos que contenham em seus constituintes, flavonóides. Flavonóides são compostos polifenólicos naturais largamente distribuídos nos vegetais superiores (angiospermas), principalmente. Muitos deles apresentam atividade biológica como, por exemplo, podem-se citar as atividades antioxidantes, antiinflamatória, antibacteriana e tanante que tem um grande potencial de exploração na área cosmética (Perruchon, 2002).

Cosméticos contendo flavonóides são tratados na patente japonesa 05163130 de 19 de dezembro de 1991 de autoria de Nakanishi e Hihara (Esu Efu Puran Jugen). Produtos cosméticos contendo 1\% de flavonóides em peso já apresentam atividade microbicida e, além disso, são hidrossolúveis e não causam irritação cutânea o que facilita sua aplicação cosmética (Rocha, 1994). 
Outro exemplo é a própolis contendo, por exemplo, teor de flavonóides variando entre $2,05 \%$ a $5,52 \%$ nos períodos de inverno a verão, respectivamente, na região de Maringá, estado do Paraná (Franco et al., 2000). Grange e Davey (1990) e Cushnie e Lamb (2005) mencionaram a forte ligação entre a concentração de flavonóides e a atividade antimicrobiana que os mesmos apresentam.

A própolis é utilizada popularmente no tratamento de infecções, em problemas de pele e, também, como antiviral (Kujumgiev et al., 1999) e anti ulceroso (Reis et al., 2000; Khalil, 2006). Ela estimula o sistema imunológico (Kosonocka, 1991; Ivanovska et al., 1995; Sforcin, 1996; Dos Santos et al., 2003; Khalil, 2006), é cicatrizante em escaras de decúbito (Azevedo et al., 1986) e apresenta atividade antibiótica frente às bactérias gram positivas (Grange; Davey 1990; Bankova et al., 1999; Kujumgiev et al., 1999; Fernandes Junior et. al., 2005). Possui ainda ações anti-séptica (Azevedo et al., 1999), antifúngica, antipirética, adstringente, antiinflamatória (Hay; Gris, 1990; Dobrowolski et al., 1991; Ruppelt et al., 1991; Burdock, 1998) e anestésica (Dos Santos et al., 2003). Também possui ação comprovada frente ao Bacillus subtilis (Grange; Davey, 1990) e Candida albicans (Ota et al., 2001; D'Auria et al., 2003). Em associação com outras plantas, serve para o tratamento de afecções do trato respiratório (Soares et al., 2006; Tavares et al., 2006).

Complementam a pesquisa o óleo de andiroba, com ação antiinflamatória (Bloise, 2003); óleo de copaíba, com vários constituintes químicos voláteis e resinosos com ação germicida (Bloise, 2003; Biavatti et al., 2006) e antiinflamatória (Falcão et al., 2005); óleo de alecrim, com ação antimicrobiana, antifúngica e antisséptica (Angioni et al., 2004; Lima et al., 2006); óleo de melaleuca, com ação bacteriostática frente à Escherichia coli, Staphylococcus aureus (Carson et al., 1995; Faoagali et al., 1998; Hada et al., 2003) e Candida albicans (Hammer et al., 2000 e 2003; Banes-Marshall et al., 2001) entre outras importantes atividades levou sua inclusão na Farmacopéia Brasileira (Brandão et al., 2006); óleo de alho, com ação antifúngica (Pai; Platt,1995; Sovova; Sova, 2002) e antihelmíntica (Amaral et al., 2006); e como exemplo de produtos industrializados com origem derivada natural tem-se um ingrediente multifuncional extraído das folhas de oliva e o farnesol, cuja ação baseia-se no poder bacteriostático frente ao Staphylococcus aureus (Akiyama et al., 2002) e Candida albicans (Ramage et al., 2002; Sato et al., 2004).

Este trabalho teve por finalidade avaliar produtos de origem natural (óleos: de copaíba, alecrim, melaleuca, alho, andiroba; própolis, e dois ingredientes de origem natural: um ingrediente multifuncional extraído de folhas de oliva e o farnesol) quanto à sua ação frente a microrganismos (Staphylococcus aureus, Escherichia coli, Pseudomonas aeruginosa e Candida albicans) utilizando a metodologia de ágar com orifício modificado.

\section{MATERIAL E MÉTODOS}

Para a pesquisa da atividade antibacteriana e antifúngica dos produtos selecionados (própolis, óleo de copaíba, de alecrim, de melaleuca, de andiroba, de alho, ingrediente multifuncional extraído de folhas de oliva e farnesol) foi realizada triagem das amostras obtidas de fornecedores de indústrias cosméticas baseada em histórico de produção e utilização dos mesmos.

As Cepas selecionadas foram: Staphylococcus aureus (ATCC 6538), Escherichia coli (ATCC 8739), Pseudomonas aeruginosa (ATCC 9027) e Candida albicans (ATCC 10231) e foram obtidas do Instituto Adolfo Lutz. A escolha das cepas foi baseada nas análises microbiológicas que produtos cosméticos necessitam para cumprir requisitos de controle de qualidade estabelecidos pela Agência Nacional de Vigilância Sanitária (ANVISA).

Os meios de cultura utilizados foram: Agar Soja Tripticaseína, Agar Sabouraud Dextrosado, Caldo Soja Tripticaseína e Caldo Sabouraud Dextrosado $\left(\mathrm{DIFCO}^{\circledR}\right)$.

Tabela 1. Perfil bacteriostático e fungistático dos produtos naturais avaliados.

\begin{tabular}{|c|c|c|c|c|}
\hline Microrganismos testados & Staphylococcus & Escherichia coli & Pseudomonas & Candida albicans \\
\hline Amostras analisadas & aureus & & aeruginosa & \\
\hline Óleo de Melaleuca & ++ & ++ & + & ++ \\
\hline Óleo de Alecrim & + & ++ & + & +++ \\
\hline Óleo de Andiroba & - & - & - & - \\
\hline Óleo de Copaíba & - & - & - & - \\
\hline Óleo de Alho & - & - & - & - \\
\hline Própolis & + & + & - & - \\
\hline $\begin{array}{l}\text { Ing. Mult. Ext. das folhas } \\
\text { de oliva }(*)\end{array}$ & + & + & - & - \\
\hline Farnesol & + & - & - & - \\
\hline
\end{tabular}

+ halo presente $<10 \mathrm{~mm}$; ++ halo presente entre 10 e $60 \mathrm{~mm} ;+++$ halo presente $>60 \mathrm{~mm}$

(*) Ingrediente Multifuncional Extraído das folhas de oliva 


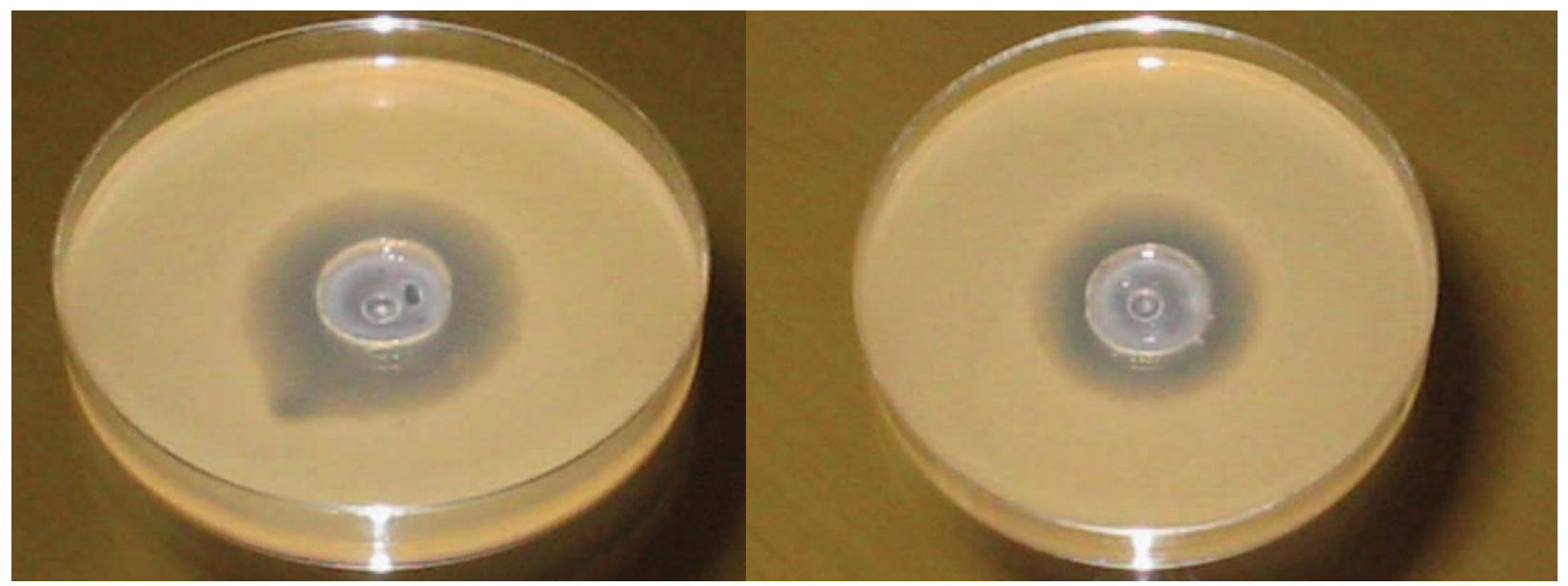

Figura 1. Halo de inibição para Staphylococcus aureus (esquerda) e para Escherichia coli (direita), em meio contendo óleo de melaleuca.

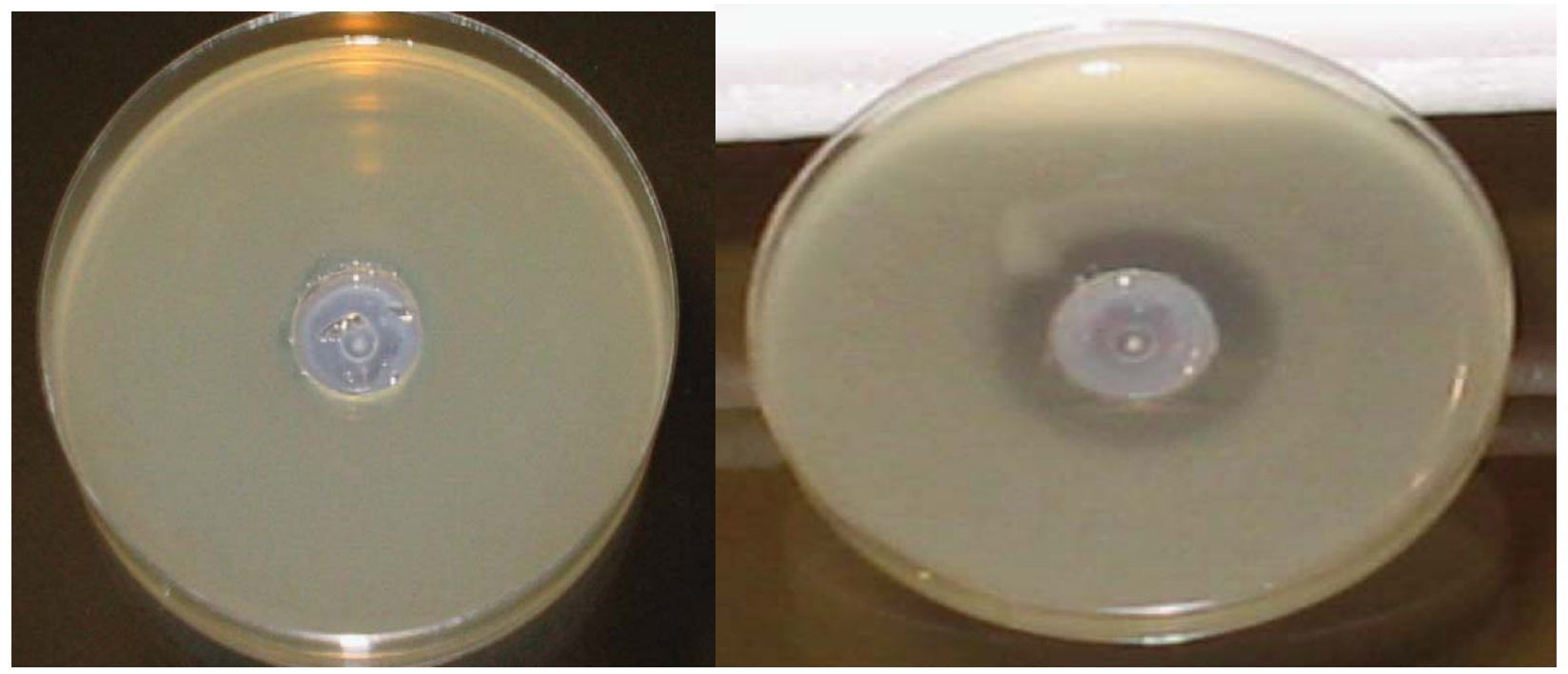

Figura 2. Halo de inibição para Pseudomonas aeruginosa (esquerda), em meio contendo óleo de melaleuca e para Candida albicans (direita).

A metodologia empregada foi a de placa em ágar com orifício - MAPO - (Fio Cruz/INCQS, 1992), que sofreu duas modificações. A primeira, onde lacrou-se o orifício com ágar em questão para que a amostra a ser aplicada posteriormente não fluísse entre o meio e a placa de petri sem, no entanto, difundir pelo meio de cultura. A segunda, onde amostras de óleo foram preparadas com adição de Tween 80 (Polissorbato 80). A utilização do Tween 80 no preparo das amostras em óleo, teve por finalidade diminuir a tensão superficial no contato do óleo (característica apolar) com o meio de cultura (característica polar) com a finalidade de permitir difusão pelo ágar.

\section{RESULTADOS E DISCUSSÃO}

Os resultados encontrados estão expostos na Tabela 1 e serão discutidos na ordem apresentada:

$\mathrm{O}$ óleo de melaleuca apresentou atividade bacteriostática e fungistática frente aos microrganismos pesquisados e foi entre as amostras testadas uma das que melhor desempenho apresentou.

De acordo com os estudos de Carson et al. (1995), esperavam-se bons resultados frente a $E$. coli e ao $S$. aureus. O método utilizado por eles foi diferente do abordado nesta pesquisa, mas os resultados foram convergentes. Com a utilização do MAPO 


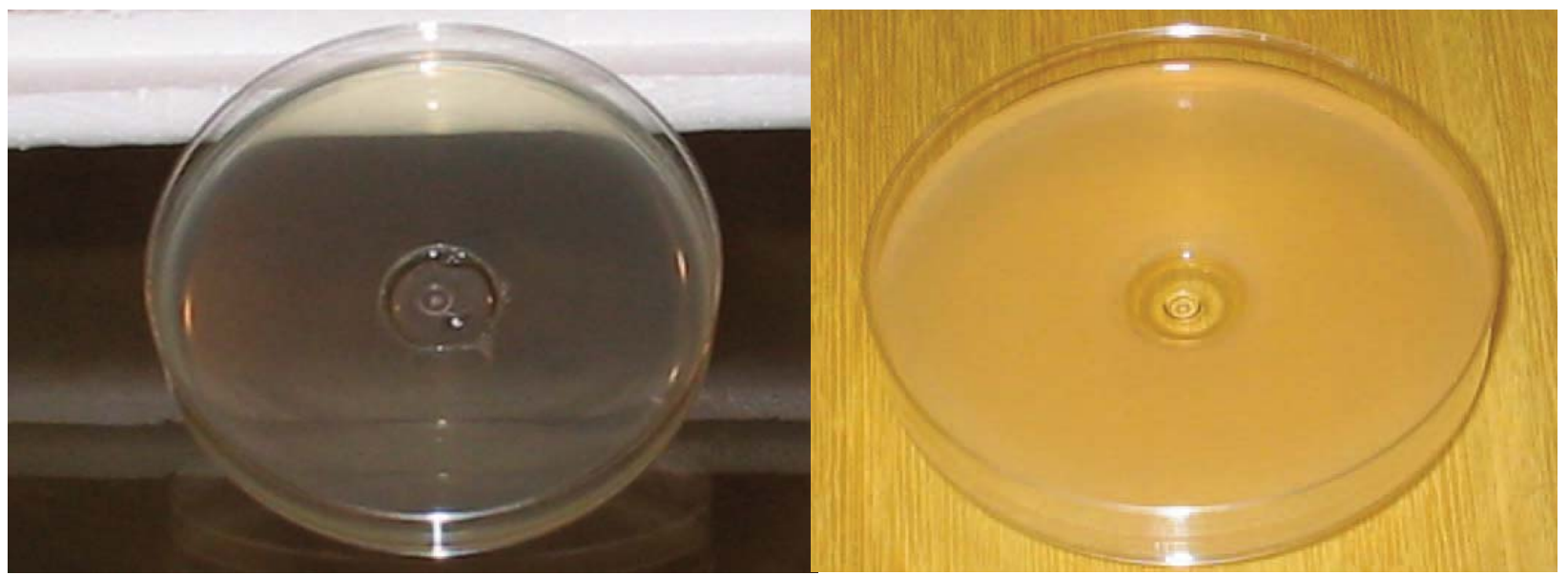

Figura 3. Efeito fungistático do óleo de alecrim frente a Figura 4. Efeito bacteriostático frente a Staphylococcus Candida albicans. aureus, em meio contendo farnesol.

pôde-se observar (Figura 1.) a susceptibilidade destas cepas quando em contato com o óleo de melaleuca. Concordância também foi observada com os resultados de Hada et al. (2003), que comprovaram a susceptibilidade de $S$. aureus. O efeito frente a Pseudomonas aeruginosa (Figura 2.) foi muito sutil quanto à produção de halo de inibição pelo MAPO o que converge também com o estudo de Longbottom et al. (2004), que comprovaram a tolerância da $P$. aeruginosa frente ao óleo. Hammer et al. (2004) verificaram, em seus estudos, que alterações nas propriedades de membrana da Candida albicans (Figura 2.) desencadearam o processo de inibição, sendo possivelmente uma explicação para a produção de halo de inibição pelo método em questão.

O óleo de alecrim tem importante papel como antimicrobiano e antifúngico devido a sua composição química (Angioni et al., 2004). Na pesquisa realizada com o MAPO obteve-se efeitos bacteriostáticos frente às três cepas testadas e efeito fungistático frente a $C$. albicans, sendo o melhor resultado o efeito fungistático observado. Como pode-se notar na figura 3 , a alíquota aplicada foi capaz de provocar inibição total da levedura.

As amostras de óleo de andiroba, Copaíba e alho não apresentaram atividade bacteriostática e fungistática frente aos microrganismos testados. Quando se incluiu o óleo de andiroba, o objetivo foi pesquisar uma possível atividade bacteriostática ou fungistática. O óleo de andiroba vem sendo muito utilizado pela indústria cosmética e uma atividade conservante seria muito positiva para sua aplicação. Já os óleos de copaíba e de alho têm cientificamente comprovados os apelos propostos por este trabalho. O óleo de copaíba possui o beta carofileno, princípio ativo que tem ação germicida (Bloise, 2003) e, portanto, deveria provocar resultado positivo (produção de halo de inibição). O óleo de alho tem ação antifúngica comprovada (Pai; Platt, 1995) e ação antibacteriana e antiviral consagradas pelo uso popular. Com o uso do MAPO tais apelos não foram observados. Não houve produção de halo de inibição com nenhum dos microrganismos testados, e sugerimos uma possível degradação de compostos com tal atividade. Não foram objetivos do trabalho as análises físico-químicas das amostras, talvez estas seriam a chave para esta incoerência nos resultados obtidos com os óleos de copaíba e alho.

A própolis apresenta eficiente atividade frente a bactérias gram positivas e atividade reduzida frente a bactérias gram negativas (Grange; Davey, 1990; Bankova et al., 1999 e Kujumgiev et al., 1999). Com a metodologia em questão obtivemos presença de halo de inibição para a cepa de $S$. aureus (bactéria gram positiva) e de E. coli (bactéria gram negativa) e ausência de halo de inibição para $P$. aeruginosa (bactéria gram negativa). Para a cepa de $C$. albicans temos ação comprovada, como antimicrobiano, da própolis (Ota et al., 2001 e D'Auria et al., 2003). A própolis tem seu efeito na atividade extracelular da fosfolipase (inibindo a enzima) e adesão fúngica nas células epiteliais (D'Auria et al., 2003). No presente experimento tal ação não pôde ser observada. A hipótese para esta divergência situa-se na diferente composição que a própolis poderia vir a ter devido a fatores climáticos, ambientais e sazonais (Sforcin et al., 1996 e 2000).

$\mathrm{O}$ ingrediente multifuncional extraído das folhas de oliva é uma rica mistura de bioflavonóides e polifenóis, cujas propriedades são anti-radicais livres, antioxidante, bacteriostático e fotoprotetor. Os resultados, com a utilização do MAPO, não evidenciaram a atividade bacteriostática sugerida pelos fabricantes. Esta divergência pode estar relacionada à possível instabilidade do produto em questão, degradação de algum de seus componentes fundamentais para a atividade, ou estar a baixo da sensibilidade do método. Lembrando-se que as matérias primas utilizadas como amostras foram conservadas como sugere o fabricante.

O farnesol (3,7,11-trimetil-2,6,10-dodecatrion1-ol), utilizado como agente bacteriostático em sabonetes, desodorantes e produtos para o tratamento da pele, é obtido através do bisabolol ( $\alpha, 4$-dimetil- $\alpha$-(4-metil-3- 
pentenil)-3-ciclohexano-1-metanol). O farnesol pode ser obtido do óleo de flor de tília, óleo de grãos de almíscar, óleo de neroli, óleo de petitgrain ou óleo de cabreúva (Spitik, 1994).

O efeito bacteriostático do farnesol já foi constatado em 1975 no Instituto Bacteriológico do Allgemeines Krankenhaus Heiss. Com auxílio do Índice de Crescimento de Contato (Teste ICC), foi constatado que o farnesol em concentração de $0,3 \%$ consegue inibir o crescimento de Staphylococcus aureus, Staphylococcus epidermidis e corinebactérias e que este efeito pode prolongar-se por aproximadamente 6 horas (Spitik, 1994). O Farnesol também é um adjuvante promissor frente às infecções dérmicas por $S$. aureus que foram tratadas com beta lactâmicos (Akiyama et al., 2002). Com o método em questão obteve-se resultado satisfatório frente à cepa de $S$. aureus convergindo com a literatura científica.

\section{CONCLUSÃO}

Com o Método de placa em Ágar com Orifício Modificado obtivemos resultados convergentes, em sua quase totalidade, com os apresentados pela literatura científica disponível. Tornou-se um método rápido, de baixo custo quando em comparação a outros métodos oferecidos e de fácil realização. Apresentou divergência em determinados resultados quando comparado com metodologias consagradas devida ao método ou as amostras analisadas que poderiam não ter a concentração e pureza de ativos produtores dos efeitos bacteriostáticos e fungistático esperados. Não foram realizados doseamento e determinação de pureza dessas amostras. Os dados foram extraídos de análises realizadas por outras instituições.

O desempenho dos produtos analisados, em sua maioria, convergiu com os resultados de experimentos anteriores publicados em literatura científica.

Dentre os produtos analisados os melhores desempenhos foram alcançados com o óleo de alecrim e com o óleo de melaleuca.

\section{REFERÊNCIAS}

Akiyama H, Oono T, Huh WK, Yamasaki O, Ogawa S, Katsuyama M, Ichikawa H, Iwatsuki K 2002. Actions of farnesol and xylitol against Staphylococcus aureus. Chemotherapy 48: 122-128.

Amaral FMM, Ribeiro MNS, Barbosa-Filho JM, Reis AS, Nascimento FRF, Macedo RO 2006. Plants and chemical constituents with giardicidal activity. Rev Bras Farmacogn 16(Supl.): 696-720.

Angioni A, Barra A, Cereti E, Barile D, Coïsson JD, Arlorio M, Dessi S, Coroneo V, Cabras P 2004. Chemical composition, plant genetic differences, antimicrobial and antifungal activity investigation of the essential oil of Rosmarinus officinalis L. J Agric Food Chem 52: 3530-3532.

Azevedo IBS, Sampaio RF, Montes JC, Contreras RLL 1986.
Tratamento de escaras de decúbito com própolis. Rev Bras Enferm 39: 7-33.

Azevedo RVP, Komesu MC, Candido RC, Salvetti C, Rezende FHC 1999. Candida sp in the oral cavity with and without lesions: maximal inhibitory dilution of própolis and periogard. Rev Microbiol 30: 335-341.

Banes-Marshall L, Cawley P, Phillips CA 2001. In vitro activity of Melaleuca alternifolia (tea tree) oil against bacterial and Candida spp. isolates from clinical specimens. $\mathrm{Br}$ J Biomed Sci 58: 139-145.

Bankova V, Christov R, Popov S, Marcucci MC, Tsvetkova I, Kujumgiev A 1999. Antibacterial activity of essencial oils from Brazilian propolis. Fitoterapia 70: 190-193.

Biavatti MW, Dossin D, Deschamps FC, Lima MP 2006. Análise de óleos-resinas de copaíba: contribuição para o seu controle de qualidade. Rev Bras Farmacogn 16: 230-235.

Bloise MI 2003. Óleos vegetais e especialidades da floresta Amazônica. Cosmetics \& Toiletries 15: 46-49.

Brandão MGL, Cosenza GP, Moreira RA, Monte-Mor RLM 2006. Medicinal plants and other botanical products from the Brazilian Official Pharmacopoeia. Rev Bras Farmacogn 16: 408-420.

Burdock GA 1998. Review of the biological properties and toxicity of bee propolis. Food Chem Toxicol 36: 347363.

Carson CF, Hammer KA, Riley TV 1995. Broth microdilution method for determining the susceptibility of Escherichia coli and Staphylococcus aureus to the essencial oil of Melaleuca alternifolia (tea tree oil). Microbios 82: 181-185.

Cushnie TP, Lamb AJ 2005. Antimicrobial activity of flavonoids. Int $J$ Antimicrob Agents 26: 343-356.

D'Auria FD, Tecca M, Scazzocchio F, Renzini V, Strippoli $\mathrm{V}$ 2003. Effect of propolis on virulence factors of Candida albicans. J Chemother 15: 454-460.

Dobrowolski JW, Vohora SB, Sharma K, Shah SA, Naqvi SA, Dandiya PC 1991. Antibacterial, antifungical, antiamoebic, antiinflammatory and antipyretic studies on propolis bee products. J Ethnopharmacol 35: 7782.

Dos Santos CR, Arcenio F, Carvalho ES, Lúcio EMRA, Araújo GL, Teixeira LA, Sharapin N, Rocha L 2003. Otimização do processo de extração de própolis através da verificação da atividade antimicrobiana. Rev Bras Farmacogn 13(Supl.): 71-74.

Falcão HS, Lima IO, Santos VL, Dantas HF, Diniz MFFM, Barbosa-Filho JM, Batista LM 2005. Review of the plants with anti-inflammatory activity studied in Brazil. Rev Bras Farmacogn 15: 381-391.

Faoagali JL, George N, Leditschke JF 1998. Antimicrobial effects of melaleuca oil. Burns 24: 383.

Fernandes Junior A, Balestrin EC, Betoni JEC, Orsi RO, Cunha MLRS, Montelli AC 2005. Propolis: antiStaphylococcus aureus activity and synergism with antimicrobial drugs. Mem I Oswaldo Cruz 100: 563566.

Fio Cruz/INCQS 1992. Manual de Saneantes. Rio de Janeiro.

Franco SL, Bruschi ML, Moura LPP, Bueno JHF 2000. Avaliação farmacognóstica da própolis da região de Maringá. Rev Bras Farmacogno 9/10: 1-10.

Grange JM, Davey RW 1990. Antibacterial properties of própolis (bee glue). JR Soc Med 83: 159-160. 
Hada T, Inoue Y, Shiraishi A, Hamashima H 2003. Leakage of $\mathrm{K}+$ ions from Staphylococcus aureus in response to tea tree oil. J Microbiol Methods 53: 309-312.

Hammer KA, Carson CF, Riley TV 2000. Melaleuca alternifolia (tea tree) oil inhibits germ tube formation by Candida albicans. Med Mycol. 38: 355-362.

Hammer KA, Carson CF, Riley TV 2003. Antifungal activity of the components of Melaleuca alternifolia (tea tree) oil. J Appl Microbiol. 95: 853-860.

Hammer KA, Carson CF, Riley TV 2004. Antifungal effects of Melaleuca alternifolia (tea tree) oil and its components on Candida albicans, Candida glabrata and Saccharommyces cerevisiae. $J$ Antimicrob Chemoth 53: 1081-1085.

Hay KD, Gris DE 1990. Propolis allergy: a cause of oral mucositis with ulceration. Oral Surg Oral Med Oral Pathol 70: 584-586.

Ivanovska ND, Dimov VB, Pavlova S, Bankova VS, Popov $S$ 1995. Immunomodulatory action of propolis. V. Anticomplementary activity of a water-soluble derivative. J. Ethnopharmacol 47: 43-135.

Khalil ML 2006. Biological activity of bee propolis in health and disease. Asian Pac J Cancer Prev 7: 22-31.

Kosonocka L 1991. Própolis fortalece o sistema imunológico. Rev Bras Apicultura 4-22.

Kujumgiev A, Tsvetkova I, Serkedjieva Y, Bankova V, Christov R, Popov S 1999. Antibacterial, antifungal and antiviral activity of propolis of different geographic origin. J Ethnopharmacol 64: 235-240.

Lima, IO, Oliveira RAG, Lima EO, Farias NMP, Souza EL 2006. Atividade antifúngica de óleos essenciais sobre espécies de Candida. Rev Bras Farmacogn 16: $197-$ 201.

Longbottom CJ, Carson CF, Hammer KA, Mee BJ, Riley TV 2004. Tolerance of Pseudomonas aeruginosa to Melaleuca alternifolia (tea tree) oil is associated with the outer membrane and energy-dependent cellular processes. J Antimicrob Chemoth 54: 386-392.

Ota C, Unterkircher C, Fantinato V, Shimizu MT 2001. Antifungal activity of propolis on different species of Candida. Mycoses 44: 375-378.

Pai ST, Platt MW 1995. Antifungal effects of Allium sativum (garlic) extract against the Aspergillus species involved in otomycosis. Lett Appl Mocrobiol 20:14-18.

Perruchon S 2002. Estudo das propriedades dos flavonóides para cosméticos através do relacionamento funçãoestrutura. Cosmetics \& Toiletries 14: 74.

Ramage G, Saville SP, Wickes BL, López-Ribot J 2002. Inhibition of Candida albicans biofilm formation by farnesol, a quorum-sensing molecule. Appl Environ Microbiol 68: 5459-5463.

Reis CMF, Carvalho JCT, Caputo LRG, Patrício KCM, Barbosa MVJ, Chieff AL, Bastos JK 2000. Atividade antiinflamatória, antiúlcera gátrica e toxicidade subcrônica do extrato etanólico de própolis. Rev Bras Farmacogn 9/10: 43-52.

Rocha PAF 1994. Preservantes. Cosmetics \& Toiletries 6: 2633.

Ruppelt BM, Pereira EF, Goncalves LC, Pereira NA 1991. Pharmacological screening of plants recommended by folk medicine as anti-snake venom. 1. Analgesic and anti-inflammatory activities. Mem I Oswaldo Cruz
86(Suppl. II): 203-205.

Sato T, Watanabe T, Mikami T, Matsumoto T 2004. Farnesol, a morphogenetic autoregulatory substance in the dimorphic fungus Candida albicans, inhibits hyphae growth through suppression of a mmitogen-activated protein quinase cascade. Biol Pharm Bull 27: 751752.

Sforcin JM 1996. Efeito da sazonalidade sobre as propriedades imunomoduladora e antibacteriana da própolis e perfil bioquímico em ratos. Botucatu. Dissertação UNESP - Faculdade de Meidicina Veterinária e Zootecnia. Botucatu - SP.

Sforcin JM, Fernandes Jr A, Lopes CA, Bankova V, Funari SR 2000. Seasonal effect on Brazilian propolis antibacterial activity. J Ethnopharmacol 73: 243-249.

Soares AKA, Carmo GC, Quental DP, Nascimento DF, Bezerra FAF, Moraes MO, Moraes MEA 2006. Avaliação da segurança clínica de um fitoterápico contendo Mikania glomerata, Grindelia robusta, Copaifera officinalis, Myroxylon toluifera, Nasturtium officinale, própolis e mel em voluntários saudáveis. Rev Bras Farmacogn 16: 447-454.

Sovova K, Sova P 2002. Pharmaceutical significance of Allium sativum L. 4. Antifungal effects. Int Dent J 52: 433437.

Spttik G 1994. Farnesol: Um bacteriostático do presente e do futuro. Cosmetics \& Toiletries 6: 44-47.

Tavares JP, Martins IL, Vieira AS, Lima FAV, Bezerra FAF, Moraes MO, Moraes MEA 2006. Estudo de toxicologia clínica de um fitoterápico a base de associações de plantas, mel e própolis. Rev Bras Farmacogn 16: 350356. 